\title{
Glyoxal and methylglyoxal in Atlantic seawater and marine aerosol particles: method development and first application during the Polarstern cruise ANT XXVII/4
}

\author{
M. van Pinxteren and H. Herrmann \\ Leibniz-Institut für Troposphärenforschung (TROPOS), Chemistry Department, Permoserstr. 15, 04318 Leipzig, Germany \\ Correspondence to: H. Herrmann (herrmann @ tropos.de)
}

Received: 13 May 2013 - Published in Atmos. Chem. Phys. Discuss.: 11 June 2013

Revised: 6 September 2013 - Accepted: 31 October 2013 - Published: 5 December 2013

\begin{abstract}
An analytical method for the determination of the alpha dicarbonyls glyoxal (GLY) and methylglyoxal (MGLY) from seawater and marine aerosol particles is presented. The method is based on derivatization with o-(2,3,4,5,6-Pentafluorobenzyl)-hydroxylamine (PFBHA) reagent, solvent extraction and GC-MS (SIM) analysis. The method showed good precision (RSD $<10 \%$ ), sensitivity (detection limits in the low $\mathrm{nL} \mathrm{L}^{-1}$ range), and accuracy (good agreement between external calibration and standard addition). The method was applied to determine GLY and MGLY in oceanic water sampled during the Polarstern cruise ANT XXVII/4 from Capetown to Bremerhaven in spring 2011. GLY and MGLY were determined in the sea surface microlayer (SML) of the ocean and corresponding bulk water (BW) with average concentrations of $228 \mathrm{ng} \mathrm{L}^{-1}$ (GLY) and $196 \mathrm{ng} \mathrm{L}^{-1}$ (MGLY). The results show a significant enrichment (factor of 4) of GLY and MGLY in the SML. Furthermore, marine aerosol particles $\left(\mathrm{PM}_{1}\right)$ were sampled during the cruise and analyzed for GLY (average concentration $0.19 \mathrm{ng} \mathrm{m}^{-3}$ ) and MGLY (average concentration $0.15 \mathrm{ng} \mathrm{m}^{-3}$ ). On aerosol particles, both carbonyls show a very good correlation with oxalate, supporting the idea of a secondary formation of oxalic acid via GLY and MGLY. Concentrations of GLY and MGLY in seawater and on aerosol particles were correlated to environmental parameters such as global radiation, temperature, distance to the coastline and biological activity. There are slight hints for a photochemical production of GLY and MGLY in the SML (significant enrichment in the SML, higher enrichment at higher temperature). However, a clear connection of GLY and MGLY to global radiation as well as to biological ac-
\end{abstract}

tivity cannot be concluded from the data. A slight correlation between GLY and MGLY in the SML and in aerosol particles could be a hint for interactions, in particular of GLY, between seawater and the atmosphere.

\section{Introduction}

Oceans cover around two-thirds of the earth and most of the manifold exchange processes between oceans and the atmosphere are only rarely understood (Cunliffe et al., 2013). Among these interaction processes, organic export from the oceans to the atmosphere via gaseous emission or via bubble bursting play an essential role as this is one pathway towards organic compounds on marine aerosol particles (Liss and Duce, 1997). The two $\alpha$-dicarbonyls, glyoxal (CHOCHO; GLY) and methylglyoxal (CH3COCHO; MGLY), have attracted increasing attention over the past years because of their potential role in secondary organic aerosol (SOA) formation (Carlton et al., 2007; Fu et al., 2008; Ervens et al., 2011). They can be produced via oxidation of volatile organic compounds (VOCs) and typical precursors are isoprene, toluene, acetylene and acetone (Fu et al., 2008; Warneck, 2003; Shaw et al., 2010). Besides secondary formation, direct emission of both GLY and MGLY to the atmosphere is also reported (Fu et al., 2008; Sinreich et al., 2010). Although the volatility of GLY and MGLY is high and these compounds are found in the gaseous phase, large shifts of GLY and MGLY in the atmosphere towards the particle phase are reported (Ervens and Volkamer, 2010). Aerosol uptake of highly soluble compounds like GLY is most efficient on 
aqueous aerosol particles, especially marine aerosol particles (Liggio et al., 2005), as the solubility of GYL and MGLY in aerosol water is expected to be strongly enhanced due to the present concentrated solutes (Lim et al., 2010). Volkamer et al. (2007) found that glyoxal uptake on aerosol particles can compete with glyoxal loss in the gas phase due to oxidation processes. Aqueous phase chemistry of GLY and MGLY in aerosol particles leads to further oxidized low volatility products such as oxalic acid (via $\mathrm{OH}$ radical reaction) and non-radical reaction including the formation of high molecular weight compounds (Tilgner and Herrmann, 2010; Ervens et al., 2011; Lim et al., 2010). Recently Sinreich et al. (2010) attributed the open ocean as an important source for GLY in the atmosphere. They measured concentrations of GLY up to $140 \mathrm{ppt}$ in the atmosphere via differential optical absorption spectroscopy (DOAS) over the remote tropical Pacific Ocean. Due to the short atmospheric lifetime of GLY and MGLY of about $2 \mathrm{~h}$ these authors assumed a local marine source. They concluded that there must be an airborne formation mechanism of GLY in form of a process at the air-sea interface or via bubble bursting. Shaw et al. (2010) recently described that the oceans also emit GLY and MGLY precursors, especially isoprene. Zhou and Mopper (1997) investigated carbonyls including GLY and MGLY in the open ocean (Sargasso Sea, Atlantic) and found that the surface of the ocean is photochemically active and produces carbonyls. These authors further suggested that besides biological processes also photochemical processes influence carbonyl abundance in seawater (Kieber and Mopper, 1987). In the atmosphere, photochemical activity (e.g., in the oxidation of isoprene) is reported to lead to the formation of GLY and MGLY (Sinreich et al., 2010). Generally, the mechanism of the production regarding GLY and MGLY and the exchange between the surface of the oceans and the atmosphere are not well understood but the ocean is assumed to play an important role (Sinreich et al., 2010).

Analytical methods for GLY/MGLY analysis in environmental samples typically include a derivatization step in order to reduce reactivity and polarity of the compounds. The most extensively used derivatization agent for atmospheric samples is 2.4-dinitrophenylhydrazine (DNPH) often in combination with solid phase extraction (SPE) and liquid chromatography-mass spectrometry (LC-MS) or ultraviolet (UV) detection (Liggio and McLaren, 2003; Kampf et al., 2011). Zhou and Mopper (1997) applied DNPH derivatization followed by SPE-LC-UV for seawater analysis. However, especially for seawater samples problems in SPE due to clogging of the cartridge due to matrix compounds are reported (Mbukwa et al., 2012). Recently a very sensitive HPLC method with fluorescence detection using dansylacetamidooxyamine as derivatization agent was presented for carbonyls in environmental water (Houdier et al., 2011). Kawamura and Ikushima (1993) developed a method for alpha dicarbonyls and atmospheric acids using BF3/butanol derivatization and gas chromatography-mass spectrometry
(GC-MS). There are several studies using o-(2,3,4,5,6Pentafluorobenzyl)-hydroxylamine (PFBHA) derivatization and GC-MS for carbonyls in atmospheric samples (Ortiz et al., 2006; Pang et al., 2013), though less studies exist for these devices in high-matrix aqueous samples. One study (Saison et al., 2009) applies PFBHA derivatization and GCMS for carbonyls in beer, however for relatively high concentrations ( $\mu \mathrm{g} \mathrm{L}^{-1}$ range). EPA method 556 applies PFBHA derivatization followed by hexane extraction and GCelectron capture detection as reference method for carbonyls (including GLY and MGLY) in drinking water.

As the open ocean and marine interactions are suggested to be an important source for the alpha-dicarbonyls in the atmosphere and because of the few available field measurements in the marine area, the aim of this work was to analyze GLY and MGLY in marine samples from the Atlantic Ocean. Firstly, the easy-to-use approach of PFBHA derivatization combined with solvent extraction and GC-MS analysis was validated for the seawater samples and aerosol particles especially regarding matrix interferences. Secondly, the method was applied to the field samples collected during a transatlantic Polarstern cruise in spring 2011. In seawater the focus was on the SML, as it is the direct interface between ocean and atmosphere. Connections of GLY/MGLY in the SML and on aerosol particles to environmental parameters such as global radiation, temperature, distance to the coastline and biological activity should help to find hints regarding the production of these compounds and a connection between these carbonyls in the ocean and in the atmosphere.

\section{Experimental}

\subsection{Cruise}

Figure 1 presents the Polarstern ANT XXVII/4 cruise plot from Capetown (South Africa) to Bremerhaven (Germany) between 20 April 2011 and 20 May 2011. Each day of the cruise is marked with a black square including 5 days backwards trajectories (blue lines), determined in a height of $30 \mathrm{~m}$ (NOAA HYSPLIT model, http://www.arl.noaa.gov, NOAA Air Resources Laboratory, Silver Spring, MD, USA). Aerosol particle sampling was performed continuously along the cruise. However due to sampling problems only 11 suitable aerosol filters could be loaded (reported in detail in section "Sampling problems and artifacts"). Water sampling was performed on 15 days, marked with a cross in Fig. 1. The green crosses present the sampling points where oceanic water sampling and clean marine aerosol sampling was co-located, meaning that SML samples were taken in the midterm of aerosol sampling.

\subsection{Sampling details}

Oceanic water sampling was performed with a rubber boat that was launched from the Polarstern ship. For SML 


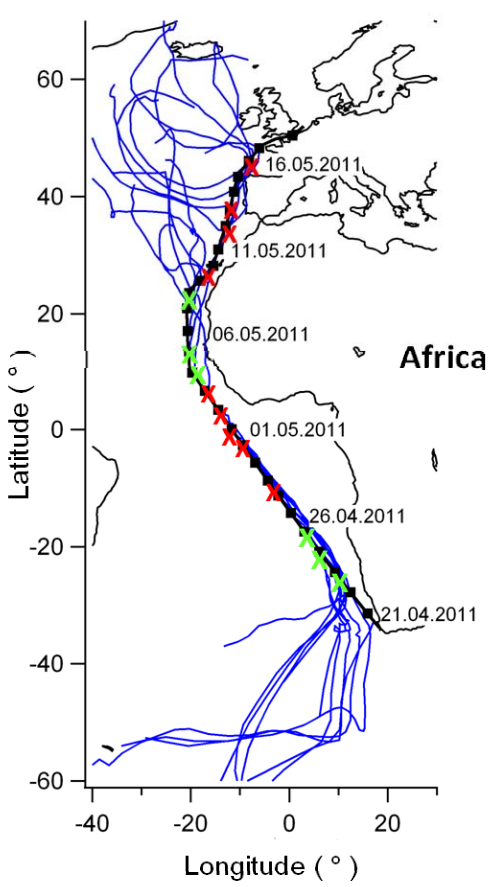

Fig. 1. Cruise plot including seawater sampling (red crosses), simultaneous seawater and aerosol particle sampling (green crosses) and backwards trajectories (blue lines).

sampling, a glass plate (sampling area $2000 \mathrm{~cm}^{2}$ ) was vertically put in the water and slowly drawn upwards. The film adheres to the surface of the glass and is taken off by framed Teflon wipers (Stolle et al., 2010; van Pinxteren et al., 2012). This sampling technique is easy to use, requires only simple equipment and provides sampling of uniform SML thicknesses of ca. $100 \mu \mathrm{m}$ (thickness = sampled volume / sampling area). Bulk water (BW) from $1 \mathrm{~m}$ depth was collected using a self-made device consisting of a glass bottle mounted on a telescopic rod that regulates sampling depth. After each sampling all material was extensively cleaned with reagent water. All water samples were stored in glass bottles and kept at $-20^{\circ} \mathrm{C}$ until analysis. Details of the sampling points for seawater sampling together with environmental parameters are listed in Table 1.

A high volume Digitel sampler DHA-80 (Walter Riemer Messtechnik, Germany) was installed on top of the observation deck at a height of ca. $30 \mathrm{~m}$. Aerosol particles $\left(\mathrm{PM}_{1}\right)$ were collected on preheated $150 \mathrm{~mm}$ quartz fiber filters (Minktell, MK 360) at a flow rate of $500 \mathrm{~L} \mathrm{~min}^{-1}$. Sampling time was $24 \mathrm{~h}$ from midnight to midnight (UTC). After sampling, the filters were stored in aluminum boxes and kept at $-20^{\circ} \mathrm{C}$ in a freezer. After the cruise they were transported in dry ice to the TROPOS laboratories in Leipzig.

Air temperature was achieved from the Scalable Automatic Weather Station SCAWS. Broadband global radiation was measured with a Kipp and Zonen CM21 pyranometer. Data are sampled with a $1 \mathrm{~Hz}$ resolution despite a $95 \%$ re- laxation time of $5 \mathrm{~s}$. The viewing angle is $180^{\circ}$ and correlates with cosine properties. Under a glass dome is a black solar radiation absorbing thermopile and 64 thermocouples. Incoming short-wave radiation heats the top and the resulting temperature gradient of thermocouples generates an electric potential which is proportional to radiation flux density.

\subsection{Analysis}

GLY $(40 \% w / w)$ and MGLY (40\%) were purchased from Sigma Chemical Co. (St Louis, MO) Stock solutions with a concentration of $1 \mathrm{mg} \mathrm{L}^{-1}$ were prepared and used for 5 days (kept in the fridge at $-20{ }^{\circ} \mathrm{C}$ ). From the stock solutions, five calibration standards were prepared in the range of $0.25-2 \mu \mathrm{g} \mathrm{L}^{-1}$ in volumes between $20 \mathrm{~mL}$ (for particle analysis) and $100 \mathrm{~mL}$ (for seawater analysis). Standards for seawater samples were always set to the same salinity as real samples (35 PSU) by adding $3.5 \mathrm{~g}$ sea salt mixture (Sigma Chemical Co.) to $100 \mathrm{~mL}$ milliQ water. Internal standards 2-Trifluormethylbenzaldehyd and 2,2,6,6Cyclohexanone (Sigma Chemical Co.) were added to the sample in a concentration of $1 \mu \mathrm{g} \mathrm{L}-1$ each. For standard addition experiments, the samples were divided in 3-5 aliquots and spiked with different amounts of standard solution. For derivatization, freshly prepared acidic PFBHA was added to the sample in a 10000 fold excess corresponding to a concentration of $1 \mu \mathrm{g} \mathrm{L}{ }^{-1}$ GLY. The free form of GLY and MGLY is in equilibrium with various forms of hydrated oligomers varying with concentration and solution $\mathrm{pH}$, however, at concentrations below $1 \mathrm{~mol} \mathrm{~L}^{-1}$ the monomeric form is dominant (Whipple, 1970). Due to acidic derivatization conditions, equilibrium is shifted towards the free form of GLY and MGLY (Liggio et al., 2005). Therefore, the measurements here represent the sum of the monomer carbonyls, its hydrated form and reversibly formed high molecular weight compounds (Kampf et al., 2012). To ensure complete derivatization, the reaction mixture was allowed to stand overnight at room temperature. For extraction, $0.5-1 \mathrm{~mL}$ of hexane was added as extraction solvent. Formation of emulsion can be a problem using LLE for complex samples, but not observed for our seawater and particle samples. After stirring for $1 \mathrm{~h}$ the hexane layer was removed, dried over sodium sulfate and transferred to a $\mathrm{GC}$ autosampler vial. In all, $2 \mu \mathrm{L}$ were injected in splitless mode into the GC-MS. A HP-5 column (Agilent technologies, Waldbronn, Germany) was applied ( $30 \mathrm{~m}$ length, $0.25 \mathrm{~mm}$ i.D. $0.25 \mu \mathrm{m}$ film thickness) and inlet temperature was set at $250^{\circ} \mathrm{C}$ and the oven program was as follows: $50^{\circ} \mathrm{C}(2 \mathrm{~min})$ with $3{ }^{\circ} \mathrm{C} \mathrm{min}^{-1}$ to $130^{\circ} \mathrm{C}$, with $10^{\circ} \mathrm{C} \mathrm{min}^{-1}$ to $280^{\circ} \mathrm{C}$. The transfer line was set at $280^{\circ} \mathrm{C}$. For GLY $m / z$ of 181 (quantifier ion) and 448 (qualifier ion), for MGLY $m / z$ of 181 (quantifier ion) and 462 (qualifier ion) were detected. Internal calibration was performed using five concentration levels and dividing the peak areas of GLY and MGLY through the peak areas of the internal standard 2-Trifluormethylbenzaldehyd. For standard 
Table 1. Seawater sampling: Sampling dates and corresponding environmental parameters

\begin{tabular}{|c|c|c|c|c|c|c|c|}
\hline \multirow{2}{*}{$\begin{array}{l}\text { Sampling } \\
\text { date }\end{array}$} & \multirow{2}{*}{$\begin{array}{l}\text { Local time } \\
\text { sampling }\end{array}$} & \multicolumn{2}{|c|}{ Coordinates } & \multirow{2}{*}{$\begin{array}{r}\text { Distance } \\
\text { to coast } \\
(\mathrm{km})^{\mathrm{a}}\end{array}$} & \multirow{2}{*}{$\begin{array}{l}\text { Air } \\
\text { temp. } \\
\left({ }^{\circ} \mathrm{C}\right)\end{array}$} & \multirow{2}{*}{$\begin{array}{l}\text { Water } \\
\text { temp. }{ }^{b} \\
\left({ }^{\circ} \mathrm{C}\right)\end{array}$} & \multirow{2}{*}{$\begin{array}{c}\text { Global } \\
\text { radiation }^{\mathrm{b}} \\
\left(\mathrm{W} \mathrm{m}^{-2}\right)\end{array}$} \\
\hline & & latitude & longitude & & & & \\
\hline 23.04.2011 & 10:05 (UTC+1) & $24^{\circ} 24.47^{\prime} \mathrm{S}$ & $9^{\circ} 18.50^{\prime} \mathrm{E}$ & 560 & 19.3 & 20.7 & 402 \\
\hline 24.04 .2011 & 12:04 (UTC) & $20^{\circ} 48.90^{\prime} \mathrm{S}$ & $6^{\circ} 4.26^{\prime} \mathrm{E}$ & 780 & 21.6 & 22.7 & 326 \\
\hline 25.04 .2011 & 12:03 (UTC) & $17^{\circ} 22.89^{\prime} \mathrm{S}$ & $3^{\circ} 2.86^{\prime} \mathrm{E}$ & 920 & 22.9 & 23.9 & 413 \\
\hline 29.04.2011 & 12:05 (UTC) & $8^{\circ} 42.44^{\prime} \mathrm{S}$ & $4^{\circ} 22.05^{\prime} \mathrm{W}$ & 1496 & 26.4 & 27.7 & 538 \\
\hline 30.04 .2011 & 13:02 (UTC) & $5^{\circ} 30.22^{\prime} \mathrm{S}$ & $7^{\circ} 3.21^{\prime} \mathrm{W}$ & 1056 & 27.8 & 28.5 & 478 \\
\hline 01.05 .2011 & 12:02(UTC-1) & $2^{\circ} 29.84^{\prime} \mathrm{S}$ & $9^{\circ} 33.70^{\prime} \mathrm{W}$ & 760 & 28.2 & 28.5 & 551 \\
\hline 02.05 .2011 & 08:05 (UTC-1) & $0^{\circ} 0.75^{\prime} \mathrm{S}$ & $11^{\circ} 37.64^{\prime} \mathrm{W}$ & 600 & 27.4 & 27.9 & $-^{\mathrm{c}}$ \\
\hline 03.05 .2011 & 12:01 (UTC-1) & $3^{\circ} 32.22^{\prime} \mathrm{N}$ & $14^{\circ} 33.95^{\prime} \mathrm{W}$ & 484 & 27.3 & 29.5 & 541 \\
\hline 04.05 .2011 & 12:04 (UTC-1) & $6^{\circ} 45.68^{\prime} \mathrm{N}$ & $17^{\circ} 14.39^{\prime} \mathrm{W}$ & 460 & 27.6 & 29.6 & 575 \\
\hline 05.05 .2011 & 12:01 (UTC-1) & $9^{\circ} 52.69^{\prime} \mathrm{N}$ & $19^{\circ} 50.63^{\prime} \mathrm{W}$ & 430 & 25.2 & 25.9 & 563 \\
\hline 08.05 .2011 & 12:04(UTC-1) & $13^{\circ} 32.49^{\prime} \mathrm{N}$ & $20^{\circ} 31.61^{\prime} \mathrm{W}$ & 380 & 22.9 & 23.8 & 552 \\
\hline 09.05 .2011 & 12:03 (UTC-1) & $23^{\circ} 39.87^{\prime} \mathrm{N}$ & $20^{\circ} 15.97^{\prime} \mathrm{W}$ & 410 & 20.4 & 21.4 & 374 \\
\hline 12.05 .2011 & 11:00(UTC-1) & $25^{\circ} 9.95^{\prime} \mathrm{N}$ & $18^{\circ} 3.28^{\prime} \mathrm{W}$ & 328 & 20.2 & 20.9 & 508 \\
\hline 13.05.2011 & $12: 19$ (UTC) & $34^{\circ} 57.29^{\prime} \mathrm{N}$ & $12^{\circ} 55.29^{\prime} \mathrm{W}$ & 498 & 18.1 & 18.2 & 489 \\
\hline 16.05 .2011 & 07:08 (UTC-1) & $37^{\circ} 34.94^{\prime} \mathrm{N}$ & $12^{\circ} 5.52^{\prime} \mathrm{W}$ & 340 & 17.0 & 17.6 & 404 \\
\hline
\end{tabular}

${ }^{\mathrm{a}}$ Shortest distance to coastline estimated via google earth; ${ }^{\mathrm{b}}$ at the sampling time; ${ }^{\mathrm{c}}$ not available.

addition, 2-4 concentration levels were added to a real sample and compared to external calibration. Oxalic acid was measured from aqueous particle extracts $(25 \%$ of the filter in $20 \mathrm{~mL}$ ) as oxalate with ion chromatography, for details see Müller et al. (2010). Dissolved organic carbon was determined from the aqueous particle extracts using a TOC-VCPH analyzer (Shimadzu, Japan) as described in van Pinxteren et al. (2009).

\section{Results and discussion}

\subsection{Method development: extraction and derivatization}

For seawater analysis, $100 \mathrm{~mL}$ of oceanic water samples (SML and BW samples) were derivatized and for aerosol analysis up to $20 \mathrm{~mL}$ aqueous extract of $25 \%$ of the filter sample were derivatized with PFBHA as described in the experimental part. Repetitive extraction of one and the same filter piece showed complete extraction in the first step. Blank problems due to the derivatization agent (especially DNPH) for carbonyls are often reported and can be overcome by re-crystallization and further cleaning of the derivatization reagent with a SPE column (Liggio and McLaren, 2003; Kampf et al., 2011). Using freshly prepared PFBHA solution blank values in the chromatograms were low, still a purification step by passing PFBHA over a SPE column (C18) led to a further reduction of the blank values. Figure 2 shows typical chromatograms for standards and samples using pre-cleaned PFBHA. While derivatized MGLY gave one peak, for derivatized GLY two isomers were found in the chromatograms. The two GLY isomers were assigned based on prior literature, the first eluting peak is referred to trans and the second peak to cis isomer (Standard Method Number 6252B, 1995), (EPA method 556, 1998). As the ratio between trans and cis GLY was constant $(1: 3)$ only cis GLY was interpreted throughout this study.

\subsection{Method validation}

The limit of detection (LOD) was determined as the concentration corresponding to the mean blank $(n=6)$ plus three times the standard deviation (Kaiser and Specker, 1956). The values in Table 2 correspond to a sample volume of $100 \mathrm{~mL}$ oceanic water and a $20 \mathrm{~mL}$ aqueous extract of $25 \%$ of the filter sample (area: $177 \mathrm{~cm}^{2}$ ) for aerosol particles. LODs can be further lowered by increasing the sample volume or reducing the extraction solvent volume (e.g., by evaporation). The LODs for seawater samples reported here are similar to other applications using GC-MS, for example by Kawamura (1993a) with LODs for carbonyls of $50 \mathrm{ng} \mathrm{L}^{-1}$ (rain and snow samples). Zhou and Mopper (1997) found lower LODs for GLY and MGLY of 3-4 $\mathrm{n} \mathrm{L} \mathrm{L}^{-1}$ after enrichment via SPE and DNPH-LC-UV analysis probably due to the very high injection volumes of $2000 \mu \mathrm{L}$ into the LC system. Using highly fluorescence derivatization agents and LC-FLD analysis, LODs of $16 \mathrm{ng} \mathrm{L}^{-1}$ (GLY) and $12 \mathrm{ng} \mathrm{L}^{-1}$ (MGLY) can be achieved without preconcentration (Houdier et al., 2011). However due to the high matrix content of real samples, mostly sample preparation steps for a combination of clean up and analyte enrichment are applied. The LODs achieved for aerosol particle analysis $(25 \%$ of filter, aqueous extract of $20 \mathrm{~mL}$, and extraction solvent of $1 \mathrm{~mL}$ ) are $353 \mathrm{ng} \mathrm{L}^{-1}$ for GLY and $259 \mathrm{ng} \mathrm{L}^{-1}$ for MGLY. The higher LODs for an aqueous extract of $20 \mathrm{~mL}$ are caused by 


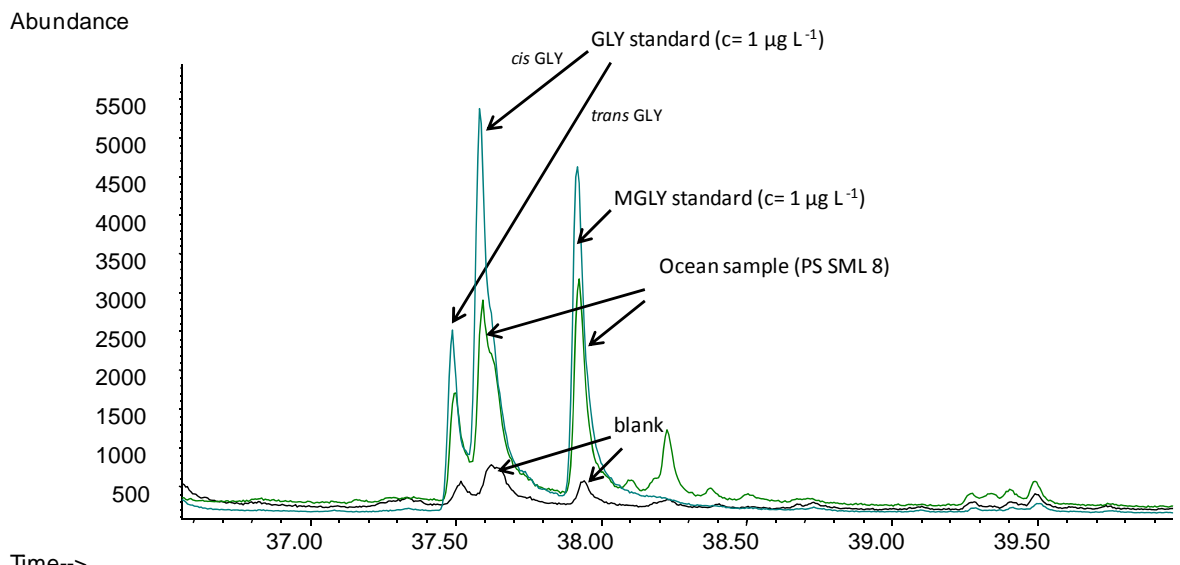

Fig. 2. SIM chromatograms of GLY and MGLY standard, ocean sample and blank (milliQ water + PFBHA), $100 \mathrm{~mL}$ sample volume each, PFBHA was pre-cleaned over a SPE C18 cartridge.

Table 2. Validation data for GLY and MGLY; relative standard deviation (RSD), extraction yields and limits of detection (LOD).

\begin{tabular}{|c|c|c|}
\hline & GLY & MGLY \\
\hline $\mathrm{RSD},(\%) n=6$ & 8.9 & 5.4 \\
\hline extraction yield (\%) & 80 & 70 \\
\hline $\operatorname{LOD}_{\text {seawater }}\left(\mathrm{ng} \mathrm{L}^{-1}\right)^{\mathrm{a}}$ & 54 & 50 \\
\hline LOD aerosolextract $\left(\mathrm{ng} \mathrm{L}^{-1}\right)^{b}$ & 353 & 259 \\
\hline $\operatorname{LOD}_{\text {aerosolparticle }}\left(\mathrm{ng} \mathrm{m}^{-3}\right)^{\mathrm{c}}$ & 0.05 & 0.04 \\
\hline
\end{tabular}

${ }^{\mathrm{a}}$ For $100 \mathrm{~mL}$ saltwater; ${ }^{\mathrm{b}}$ for $20 \mathrm{~mL}$ aqueous extract; ${ }^{\mathrm{c}}$ for $545 \mathrm{~m}^{3}$ air volume.

higher blank values from the filter material. The LODs for the aerosol particle analysis reported here are slightly lower compared to Kampf et al. (2011) applying DNPH-LC-MS analysis (510 $\mathrm{ng} \mathrm{L}^{-1}$ for GLY, $620 \mathrm{ng} \mathrm{L}^{-1}$ for MGLY) and similar to Kawamura (1993a). Solvent extraction yields in this work were estimated by three successive extraction steps with hexane regarding the sum of them as $100 \%$ value. The extraction yields in the first step were $80 \%$ for GLY $(76 \%$ for $100 \mathrm{~mL} ; 82 \%$ for $20 \mathrm{~mL}$ ) and $70 \%$ for MGLY $(65 \%$ for $100 \mathrm{~mL} ; 75 \%$ for $20 \mathrm{~mL}$ ). Repeatability, determined by 6 fold measurements of aqueous standards with a concentration of $1 \mu \mathrm{g} \mathrm{L}^{-1}$, was very good with relative standard deviations (RSD) below $10 \%$. To test for matrix interferences, internal calibration was compared with standard addition and the graphs are shown in Fig. 3. No interferences with the matrix were found as the slopes of the calibration curves are very close (same for MGLY). Therefore, external calibration could be applied to the oceanic water samples as well as to the aqueous aerosol extracts.

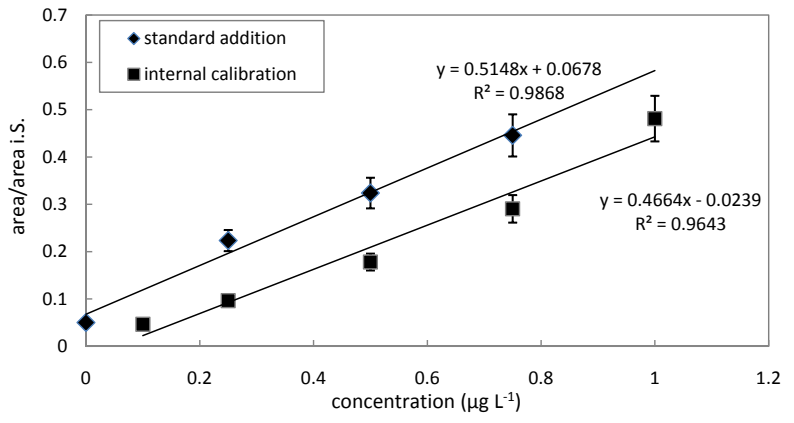

(a)

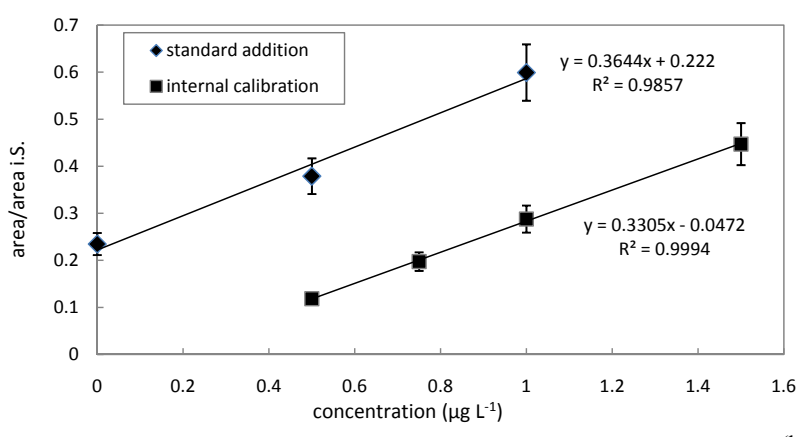

(b)

Fig. 3. Calibration curve for internal calibration and standard addition for GLY (a) $100 \mathrm{~mL}$ seawater sample, (b) $20 \mathrm{~mL}$ aqueous extract of aerosol particle sample.

\subsection{Field measurements}

\subsubsection{GLY and MGLY in Atlantic seawater}

The results for GLY and MGLY concentrations in SML and bulk water are listed in Table 3. Average concentration of GLY in the SML was $330 \mathrm{~nL}^{-1}\left(123-616 \mathrm{ng} \mathrm{L}^{-1}\right)$. SML 
concentration for MGLY were on average slightly lower (261 $\mathrm{ng} \mathrm{L}^{-1}$ ) with a higher fluctuation (77-760 $\left.\mathrm{n} \mathrm{L}^{-1}\right)$. In $\mathrm{BW}$, average concentrations were $121 \mathrm{ng} \mathrm{L}^{-1}$ (GLY) and $94 \mathrm{ng} \mathrm{L}^{-1}$ (MGLY). MGLY also showed higher fluctuation and in six BW samples MGLY concentrations were below LOD. There was a weak correlation between GLY and MGLY concentrations in the SML $\left(R^{2}=0.28\right)$, while no correlation was found for these compounds in BW. The enrichment factor $\left(\mathrm{EF}=c_{\mathrm{SML}} / c_{\mathrm{BW}}\right)$ for GLY and MGLY in the SML varied strongly but was mostly $>1$. The average EF for both compounds was ca. 4 and $\mathrm{EF}_{\mathrm{GLY}}$ and $\mathrm{EF}_{\mathrm{MGLY}}$ are slightly correlated $\left(R^{2}=0.30\right)$. The actual EF is in fact even higher considering that for several BW samples GLY and especially MGLY concentrations were below LOD, whereas SML concentrations were detectable. Presently, there are few measured GLY and MGYL concentrations in real seawater samples available from literature. In one application from Zhou and Mopper (1997) GLY and MGLY were measured (besides other aldehydes) in the Sargasso Sea (Atlantic Ocean, near Bahamas). The concentrations are in the same range (lower $\mathrm{nM}$ range) compared to the data presented here. The authors also observed enrichment of GLY and MGYL in the SML with higher average enrichment factors than found in the present study but also with higher variability (EF: 121 for GLY; EF: 2-13 for MGLY). Regarding the formation and enrichment of carbonyls in seawater, photochemical production has been reported to be a major source of carbonyls in surface water (Kieber et al., 1990). Zhou and Mopper (1997) found higher photoproduction rates of carbonyls in SML compared to BW. Moreover, microbial activity is discussed to be an important factor influencing carbonyl abundance in seawater (Zhou and Mopper, 1997; Kieber and Mopper, 1987). Microorganisms may either take up carbonyl compounds or release them. Kieber and Mopper (1987) suggested microbial activity to be rather a sink than a source in well-oxygenated conditions such as the SML. The enrichment of GLY and MGLY found in this work might be an indicator for photochemical production of the carbonyls in the SML, as the SML is more exposed to sunlight. However, only weak correlations were found between global radiation and concentration of GLY and MGLY in the SML as well as enrichment of GLY/MGLY $\left(R^{2} \sim 0.2\right.$, Figs. S1-S4). Global radiation is slightly correlated to air temperature within the SML sampling time $\left(R^{2}=0.39\right.$, Fig. S5). Air temperature is strongly correlated to water temperature $\left(R^{2}=0.98\right.$, values in Table 1). A correlation to SML concentrations of GLY and MGLY to air temperature was not found (Figs. S7S8). However, enrichment of the two carbonyls seems to be connected to air temperature, indicated by a positive correlation between $\mathrm{EF}$ and temperature $\left(R^{2}=0.4\right.$, Figs. S9S10). A connection of GLY and MGLY to biological activity was evaluated by correlating GLY and MGLY concentrations to Chlorophyll $a(\mathrm{Chl} a)$ as an indicator for biological activity. Chl $a$ satellite data - provided by the Ocean Color Web from NASA (http://oceancolor.gsfc.nasa.gov/), radius of $78 \mathrm{~km}, n=10-$ showed no uniform trend regarding $\mathrm{Chl}$ $a$ and GLY/MGLY concentration or enrichment in the water samples (Figs. S11-S14). However, it must be mentioned that $\mathrm{Chl} a$ is a very broad indicator for biological activity and does not reflect carbonyl specific microorganisms. Moreover, satellite measurements are sensitive to cloud cover. Therefore, an important issue in further sampling campaigns is the development of analytical analysis of biologic pigments such as Chl $a$ and others. Zhou and Mopper (1997) reported that concentrations of carbonyls are higher in coastal areas compared to the open ocean but enrichment in the SML showed the opposite trend (higher enrichment in open ocean, lower enrichment in coastal waters). This is in agreement to Carlson (1983), who reported the same trend for dissolved organic carbon (DOC) in general. Regarding GLY and MGLY in the present work, the trend for decreasing concentrations in the SML towards the open ocean is weak $\left(R^{2}=0.14\right.$ for GLY, $R^{2}=0.05$ for MGLY, Figs. S15-S16). Higher enrichment towards the ocean was observed as very slight for $\operatorname{MGLY}\left(R^{2}=0.2\right.$, Fig. S18).

In summary the enrichment factor $>1$ implies photochemical production of the carbonyls that is also supported by the trend of a higher enrichment at higher temperatures. However, a direct correlation to global radiation was less pronounced. No indications of biological carbonyl production or depletion could be concluded from our data. Furthermore, only small dependencies regarding carbonyls in seawater and the distance to coastline were found.

\subsubsection{GLY/MGLY on aerosol particles}

\section{Sampling problems and artifacts}

As reported in Sect. 2.1, $\mathrm{PM}_{1}$ aerosol particles were collected along the entire cruise. For several sampling days and at certain wind directions, the exhaust plume affected the filter sampling, resulting in a contamination of the filters. Therefore, all filters with elemental carbon values above $60 \mathrm{ng} \mathrm{m}^{-3}$ were excluded. Furthermore, some filters needed to be excluded due to water entrance into the Digitel sampler inlet at high wind speeds resulting in wet filters. Overall we achieved 11 filter samples ( $24 \mathrm{~h}$ sampling each) which were suggested to be of marine origin due to their low values of elemental carbon and air masses from the open ocean.

At the moment it is not possible to assess positive and negative artifacts during aerosol sampling and the GLY and MGLY concentrations reported here may be affected by uncertainties such as adsorption of organic vapors, volatilization or further reactions of the analytes. However, care was taken that directly after sampling and during transport to the laboratories, filters were cooled throughout at $-20^{\circ} \mathrm{C}$ until analysis. Quartz filters are employed in similar applications for the sampling of GLY and MGLY (Kawamura et al., 2010; Pavuluri et al., 2010; Li and Yu, 2005). Miyazaki et al. (2010) reported that levels of field blanks were generally 
Table 3. Surface microlayer thickness, GLY and MGLY concentrations in surface microlayer (SML) and bulk water (BW) and corresponding enrichment factor $(\mathrm{EF})$.

\begin{tabular}{crrrr|rrr}
\hline $\begin{array}{c}\text { Sampling } \\
\text { date }\end{array}$ & $\begin{array}{r}\text { SML thickness } \\
(\mu \mathrm{m})\end{array}$ & & GLY & & & MGLY & \\
\hline & & SML & BW & EF & SML & BW & EF \\
\hline 23.04 .2011 & 132 & 257 & $<$ LOD & $>5.8$ & 234 & $<$ LOD & $>5.9$ \\
24.04 .2011 & 122 & 239 & 71.1 & 3.4 & 111 & $<$ LOD & $>3.4$ \\
25.04 .2011 & 132 & 123 & 83.8 & 1.5 & 130 & $<$ LOD & $>1.5$ \\
29.04 .2011 & - & 312 & 134 & 2.3 & 172 & 50.9 & 3.4 \\
30.04 .2011 & 142 & 419 & 59.4 & 7.1 & 325 & $<$ LOD & $>8.1$ \\
01.05 .2011 & 146 & 284 & 75.2 & 3.8 & 145 & 51.4 & 2.8 \\
02.05 .2011 & 128 & 453 & 75.1 & 6.0 & 760 & 246 & 3.1 \\
03.05 .2011 & 127 & 276 & 69.7 & 4.0 & 305 & 68.1 & 4.5 \\
04.05 .2011 & 93 & 492 & 93.7 & 5.3 & 650 & $<$ LOD & $>16$ \\
05.05 .2011 & 93 & 389 & 101 & 3.9 & 179 & 213 & 0.8 \\
08.05 .2011 & 108 & 360 & 93.9 & 3.8 & 253 & 150 & 1.7 \\
09.05 .2011 & 134 & 208 & 114 & 1.8 & 225 & 143 & 1.6 \\
12.05 .2011 & 111 & 204 & 216 & 0.9 & 77.2 & $<$ LOD & $>1.9$ \\
13.05 .2011 & - & 616 & 257 & 2.4 & 199 & 63.8 & 3.1 \\
16.05 .2011 & 113 & 313 & 322 & 1.0 & 143 & 186 & 0.8 \\
average & - & 330 & 121 & 3.5 & 94.2 & 4.0 & - \\
\hline
\end{tabular}

* For average values concentrations < LOD were set at LOD (GLY: $54 \mathrm{ng} \mathrm{L}^{-1}$; MGLY: $50 \mathrm{ng} \mathrm{L}^{-1}$ ).

less than $17 \%$ of mass concentrations for diacids and related compounds (such as GLY and MGLY) for quartz filters.

\section{GLY/MGLY concentrations on aerosol particles}

The concentrations of GLY and MGLY in the $\mathrm{PM}_{1}$ samples (Fig. 4, Table S1) ranged between $0.11-0.41 \mathrm{ng} \mathrm{m}^{-3}$ (GLY) and $0.06-0.29 \mathrm{ng} \mathrm{m}^{-3}$ (MGLY). Due to strong acidic conditions during derivatization, GLY and MGLY values represent the sum of the monomer carbonyls, its hydrated form and reversibly formed high molecular weight compounds (Liggio et al., 2003). The very good correlation between GLY and MGLY $\left(R^{2}=0.82\right)$ suggest a similar transport and/or formation mechanism for these two compounds in the atmosphere. GLY concentrations are always slightly higher than MGLY (factor 1.3) which might be due to the increased solubility of GLY $K_{\mathrm{H}}=3.6 \times 10^{5} \mathrm{M} \mathrm{atm}^{-1}$; MGLY: $K_{\mathrm{H}}=$ $3.7 \times 10^{3} \mathrm{M} \mathrm{atm}^{-1}$ data from Fu et al. (2008) which might lead to a stronger uptake to the aerosol phase. As GLY and MGLY are short-living compounds in the atmosphere with an atmospheric lifetime of ca. $2 \mathrm{~h}$ in an marine environment (Sinreich et al., 2010), GLY and MGLY are not expected to originate from continental sources but rather from the open sea. The concentrations for GLY and MGLY reported here are in the same order of magnitude as reported for marine aerosol particles by other authors in different places. No measured GLY and MGLY data for aerosol particles over the Atlantic Ocean were found in the literature. Kawamura et al. (2010) observed GLY (average: $0.55 \mathrm{ng} \mathrm{m}^{-3}$ ) and MGLY (average $0.31 \mathrm{ng} \mathrm{m}^{-3}$ ) on Arctic aerosol particles showing a seasonal variation with a peak in April being produced during polar sunrise events. Over the western North Pacific the concentration of MGLY concentrations were on average $0.5 \mathrm{ng} \mathrm{m}^{-3}$ while GLY concentrations were much lower $\left(0.06-0.12 \mathrm{ng} \mathrm{m}^{-3}\right.$ ) (Miyazaki et al., 2010). In tropical India aerosol particles GLY and MGLY were found in concentrations between 4 and $23 \mathrm{ng} \mathrm{m}^{-3}$ (Pavuluri et al., 2010). An explanation for the higher concentrations could be that the air was mainly coming from the Arabian Sea, the Indian Ocean but also partly continentally influenced. Generally higher concentrations of GLY and MGLY on aerosol particles are reported in anthropogenic areas compared to remote areas. In megacities, GLY and MGLY can be up to hundreds of $\mathrm{ng} \mathrm{m}^{-3}$ (for example up to $218 \mathrm{ng} \mathrm{m}^{-3}$ in Hong Kong ( $\mathrm{Li}$ and Yu, 2005; Ho et al., 2007; Kawamura and Yasui, 2005). Liggio and McLaren (2003) reported the alpha dicarbonyls in the lower $\mathrm{ng} \mathrm{m}^{-3}$ range at urban and rural sites in Canada (GLY: 0.43-3.3 $\mathrm{ng} \mathrm{m}^{-3}$; MGLY: $0.03-1.2 \mathrm{ng} \mathrm{m}^{-3}$ ). At a background measurement site in the Rhine-Main area in Germany, concentration were in average $1 \mathrm{ng} \mathrm{m}^{-3}$ for GLY and $1.4 \mathrm{ng} \mathrm{m}^{-3}$ for MGLY (Kampf et al., 2011). In a correlation of GLY and MGLY to $\mathrm{NO}_{x}$ the authors showed an anthropogenic influence on the SOA formation potential of GLY and MGLY. In another study the authors found $0.81 \mathrm{ng} \mathrm{m}^{-3}$ for GLY and $0.31 \mathrm{ng} \mathrm{m}^{-3}$ for MGLY in a boreal forest in Finland (Kampf et al., 2012). In a very recent study, Kawamura et al. (2013) presented GLY and MGLY aerosol concentrations with a maximum of $70 \mathrm{ng} \mathrm{m}^{-3}$ and $120 \mathrm{ng} \mathrm{m}^{-3}$ at Mt. Tai (North China). The corresponding 


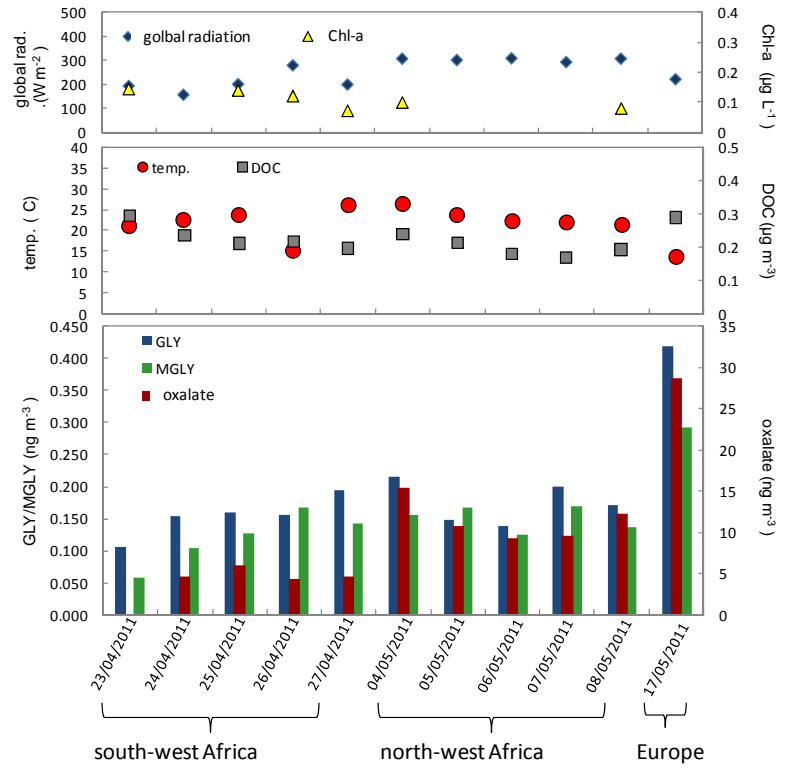

Fig. 4. Concentration of GLY, MGLY and oxalate together with DOC and environmental parameters.

gas phase concentrations were by a factor of 10-20 higher. They found a strong correlation to levoglucosan, suggesting biomass burning to be an important source for alpha dicarbonyls.

For the data presented here, a very good correlation between the two carbonyls and oxalate was found (Fig. 5), regarding the absolute concentrations as well as their DOC fraction on the aerosol particles. The strong correlation is partly caused by the last sampling point close to Europe (highest GLY, MGLY and oxalate concentrations) but still pronounced without this data point $\left(R^{2}=0.4\right.$ for GLY and MGLY). The correlation between GLY and MGLY to oxalate might show a linkage towards a secondary formation of oxalic acid via these alpha dicarbonyls, that is a detailed described pathway in the literature (Tilgner and Herrmann, 2010; Ervens et al., 2011). Tilgner and Herrmann (2010) showed that oxalic acid is formed preferably in the atmospheric aqueous phase due to aldehyde precursors such as GLY and MGLY. Rinaldi et al. (2011) suggested that cloudmediated oxidation of gaseous GLY might be an important source for oxalate on aerosol particles. Oxalate concentrations in this work are by a factor of 29 higher than the sum of GLY and MGLY concentrations. This might be due to multiple potential precursors for oxalic acid or higher accumulation of oxalic acid in the aerosol particles due to its much lower volatility compared to GLY and MGLY. Positive correlations between alpha dicarbonyls and oxalic acid were also reported by Kawamura et al. (2013) regarding aerosol particles from Mt. Tai in China as well as for Arctic aerosol particles where oxalate concentrations were on average by a factor of 19 higher than GLY and MGLY together (Kawamura et al., 2010).

Regarding the data presented here, the last sampling point (17 May 2011) was very close to European mainland (Fig. 1) measurements. Although air masses were marine and EC concentrations below $60 \mathrm{ng} \mathrm{m}^{-3}$, the higher concentration of GLY and MGLY (and also oxalate) might be caused by stronger anthropogenic influences such as enhanced ship traffic in this region. Different authors (Liggio and McLaren, 2003; Kampf et al., 2011) report stronger GLY and MGLY abundance in higher anthropogenic influenced areas probably due to an increased concentration of aromatic precursors. Also for oxalic acid, higher concentrations are reported in areas where a continental influence becomes noticeable (Warneck, 2003; Kawamura and Usukura, 1993b). Probably other than ocean driven mechanisms and different precursors are important in this area close to Europe. Disregarding the last sampling point, a positive correlation between GLY and MGLY concentration to temperature $\left(R^{2}=0.42, R^{2}=0.30\right.$, respectively, $n=10$, Figs. S19-S20) was found. Global radiation correlated to MGLY $\left(R^{2}=0.42 ; n=10\right.$, Fig. S21) but weakly to GLY $\left(R^{2}=0.10, n=10\right.$, Fig. S22). Photochemical production from precursors such as isoprene is reported to be the dominant source for GLY and MGLY, but photolysis and oxidation with $\mathrm{OH}$ also represent sinks for these carbonyls in the atmosphere (Fu et al., 2008). Besides photochemical activity, Ervens and Volkamer (2010) revealed further important parameters that strongly affect GLY on aerosol particles such as particle constitution (liquid water content, $\mathrm{pH}$, chemical composition). Therefore, a combination of environmental factors might affect GLY and MGLY abundance on aerosol particles. For oxalate concentrations determined in this work, correlation to global radiation was quite strongly pronounced $\left(R^{2}=0.60, n=10\right.$, Fig. S23) indicating photochemical production to be a dominant source. This might indicate that GLY and MGLY production could result from the photo-oxidation of a VOC precursor in the gas phase.

In contrast to seawater, where no connection to $\mathrm{Chl} a$ was found, a negative correlation of GLY and MGLY to Chl $a$ was observed for GLY $\left(R^{2}=0.54\right.$, Fig. S24 $)$ and less pronounced for MGLY $\left(R^{2}=0.28, n=6\right.$, Fig. S25). Also oxalic acid on aerosol particles showed a slightly negative correlation to Chl $a\left(R^{2}=0.28, n=6\right.$, Fig. S26). Miyazaki et al. (2010) also observed increased concentrations for GLY on marine aerosol particles in times of lower biological activity, while MGLY concentrations were hardly affected. One possible explanation for the diminished concentrations of GLY and MGLY in the aerosol particles without changes in seawater concentrations could be changes in the gas phase chemistry depending on biological activity. Biological activity could affect the concentrations of the carbonyls and their precursors in the gas phase leading to a reduced production and/or stronger degradation of the alpha dicarbonyls and affecting their partitioning between gas and aerosol phase. However 


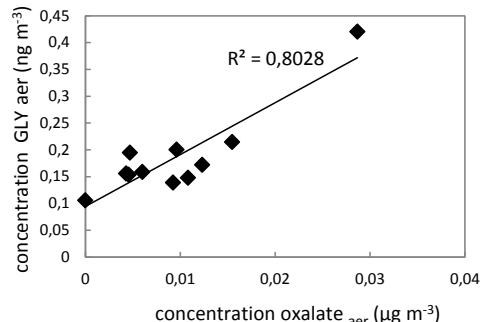

(a)

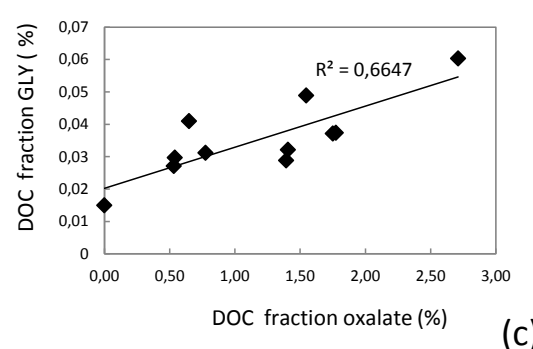

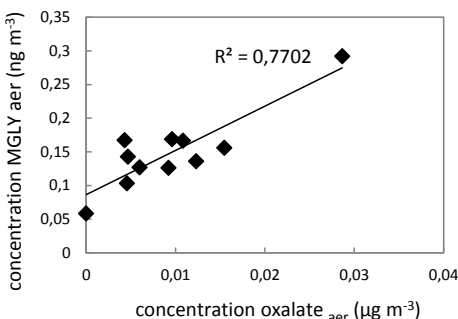

(b)

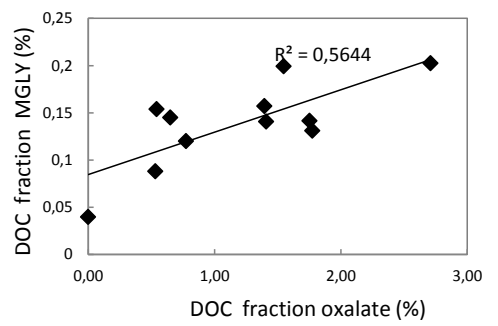

(d)

Fig. 5. Correlation of GLY/MGLY and oxalate: (a) and (b) concentration, (c) and (d) DOC fraction. * DOC fraction was calculated from GLY, MGLY and oxalate concentrations and their contribution to DOC concentrations on a carbon basis.

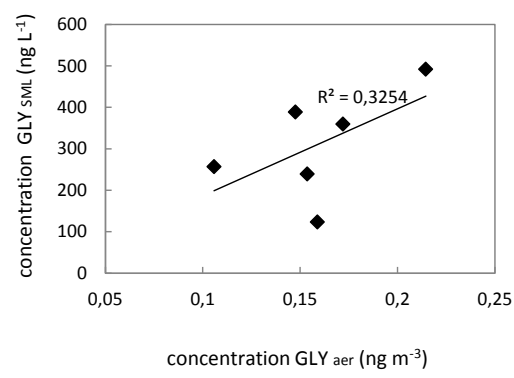

(a)

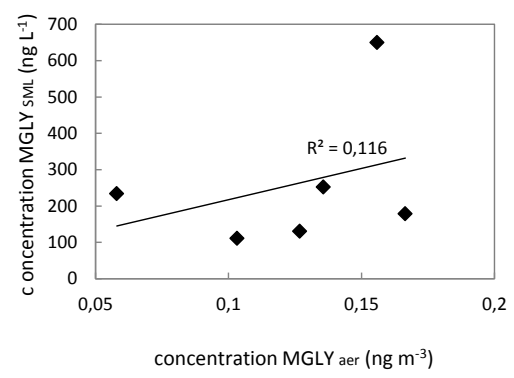

(b)

Fig. 6. Correlation of (a) GLY and (b) MGLY in SML and in aerosol particle.

due to the limited data set and the lack of gas phase measurements clearly more research is needed on this subject.

\section{GLY/MGLY in the SML and aerosol}

Within the Polarstern cruise there were six sampling dates when seawater and clean marine aerosol particles sampling was co-located, meaning that SML sampling was in the midterm of the $24 \mathrm{~h}$ aerosol sampling time. These sampling dates are illustrated with a green cross in Fig. 1. A positive correlation between the carbonyls in the SML and in aerosol particles was found for GLY $\left(R^{2}=0.33\right.$; less pronounced for MGLY: $R^{2}=0.12$ ) presented in Fig. 6 . There are multiple ways of exchange processes between oceans and the atmosphere for the carbonyls that could be the reason for a positive correlation. Turekian et al. (2003) summarized three main processes for sea-air transfer of organics:
(1) gaseous transfer from the ocean into the atmosphere and gas-to-particle conversion, (2) incorporation of material from the organic rich SML during wind driven aerosol production, and (3) accumulation of organics to the surface of bubbles and its subsequent injection to the atmosphere (bubble bursting). Although the last process is mostly expected for surface active material, also non-surface active organics can be associated with the surface active agent (Duce, 1976). Generally, all these processes are possible for GLY and MGLY as well as for their precursors - including subsequent deposition back to the ocean. Due to the high solubility of GLY and MGLY their net flow is expected from air to sea (Zhou and Mopper, 1990). Sinreich et al. (2010) observed high concentrations of gaseous GLY over the Pacific Ocean and suggested an airborne source of GLY in the form of a process at the air-sea interface or by a bubble bursting process. 
In summary, the slight correlation of the alpha dicarbonyls in the SML and in the aerosol particles reported here could be a hint for interactions of these compounds - especially GLY - in seawater and in the atmosphere although specific mechanisms cannot be concluded from this work.

\section{Conclusions}

This work presents a suitable and easy-to-use method for the analysis of GLY and MGLY in seawater and aerosol particles. To our knowledge, these data present the first measured GLY and MGLY concentrations on Atlantic aerosol particles and the corresponding seawater samples. In seawater, the enrichment in the SML implies a photochemical production of GLY and MGLY though a clear connection to global radiation was not observed. GLY and MGLY on marine aerosol particles are strongly connected to each other, suggesting similar formation mechanisms. Moreover they are both correlated to oxalate. A negative correlation of GLY and MGLY on aerosol particles to biological activity was found. As no connection between SML concentrations of the carbonyls and Chl $a$ was observed, the reason might be due to changes in gas phase chemistry of the carbonyls and their precursors. The results of GLY and MGLY in marine aerosol particles and in the ocean water give a first insight towards the interaction processes between ocean and atmosphere, though detailed mechanisms and net fluxes cannot be concluded from our data. Further investigations of important precursors of GLY and MGLY (especially isoprene), gas phase sampling of the carbonyls and a larger data set are necessary for a better understanding of GLY and MGLY interactions between air and sea.

\section{Supplementary material related to this article is available online at http://www.atmos-chem-phys.net/13/ 11791/2013/acp-13-11791-2013-supplement.pdf.}

Acknowledgements. The authors acknowledge the team from the Polarstern ANT XXVII/4 cruise, M. Brückner for global radiation measurements, S. Fuchs for sampling, M. Voyevoda for technical assistance and the Bundesministerium fuer Bildung und Forschung (BMBF) for funding within the SOPRAN project (FKZ03F0662-J).

Edited by: R. McLaren

\section{References}

Carlson, D. J.: Dissolved Organic Materials in Surface Microlayers - Temporal and Spatial Variability and Relation to Sea State, Limnol. Oceanogr., 28, 415-431, 1983.
Carlton, A. G., Turpin, B. J., Altieri, K. E., Seitzinger, S., Reff, A., Lim, H. J., and Ervens, B.: Atmospheric oxalic acid and SOA production from glyoxal, Results of aqueous photooxidation experiments, Atmos. Environ. 41, 7588-7602, doi:10.1016/j.atmosenv.2007.05.035, 2007.

Cunliffe, M., Engel, A., Frka, S., Gasparovic, B., Guitart, C., Murrell, J. C., Salter, M., Stolle, C., Upstill-Goddard, R., and Wurl, $\mathrm{O}$ : Sea surface microlayers, A unified physicochemical and biological perspective of the air-ocean interface, Prog. Oceanogr., 109, 104-116, doi:10.1016/j.pocean.2012.08.004, 2013.

Duce, R. and Hoffmann, E. J.: Chemical fractionation at the air/sea interface, Annu. Rev. Earth Planet Sci., 4, 187-228, 1976.

EPA method 556: Determination of carbonyl compounds in drinking water by pentafluorobenzylhydroxylamine derivatization and capillary gas chromatography with electron capture detection, National exposure research laboratory office of research and development US Environmental Protection Agency Cincinnati, Ohio 45268, 1998.

Ervens, B. and Volkamer, R.: Glyoxal processing by aerosol multiphase chemistry: towards a kinetic modeling framework of secondary organic aerosol formation in aqueous particles, Atmos. Chem. Phys., 10, 8219-8244, doi:10.5194/acp-10-8219-2010, 2010.

Ervens, B., Turpin, B. J., and Weber, R. J.: Secondary organic aerosol formation in cloud droplets and aqueous particles (aqSOA), a review of laboratory, field and model studies, Atmos. Chem. Phys., 11, 11069-11102, doi:10.5194/acp-1111069-2011, 2011.

Fu, T. M., Jacob, D. J., Wittrock, F., Burrows, J. P., Vrekoussis, M., and Henze, D. K.: Global budgets of atmospheric glyoxal and methylglyoxal, and implications for formation of secondary organic aerosols, J. Geophys. Res.-Atmos., 113, D15303, doi:10.1029/2007jd009505, 2008.

Ho, K. F., Cao, J. J., Lee, S. C., Kawamura, K., Zhang, R. J., Chow, J. C., and Watson, J. G.: Dicarboxylic acids, ketocarboxylic acids, and dicarbonyls in the urban atmosphere of China, J. Geophys. Res.-Atmos., 112, D22s27, doi:10.1029/2006jd008011, 2007.

Houdier, S., Barret, M., Domine, F., Charbouillot, T., Deguillaume, L., and Voisin, D.: Sensitive determination of glyoxal, methylglyoxal and hydroxyacetaldehyde in environmental water samples by using dansylacetamidooxyamine derivatization and liquid chromatography/fluorescence, Anal. Chim. Ac., 704, 162173, doi:10.1016/j.aca.2011.08.002, 2011.

Kaiser, H. and Specker, H.: Bewertung und Vergleich von Analysenverfahren, Fresenius Zeitschrift für Analytische Chemie, 149, 46-66, doi:10.1007/bf00454145, 1956.

Kampf, C. J., Bonn, B., and Hoffmann, T.: Development and validation of a selective HPLC-ESI-MS/MS method for the quantification of glyoxal and methylglyoxal in atmospheric aerosols (PM2.5), Anal. Bioanal. Chem., 401, 3115-3124, doi:10.1007/s00216-011-5192-z, 2011.

Kampf, C. J., Corrigan, A. L., Johnson, A. M., Song, W., Keronen, P., Königstedt, R., Williams, J., Russell, L. M., Petäjä, T., Fischer, H., and Hoffmann, T.: First measurements of reactive $\alpha$-dicarbonyl concentrations on PM2.5 aerosol over the Boreal forest in Finland during HUMPPA-COPEC 2010 - source apportionment and links to aerosol aging, Atmos. Chem. Phys., 12, 6145-6155, doi:10.5194/acp-12-6145-2012, 2012. 
Kawamura, K.: Identification of C-2-C-10 omega-oxocarboxylic acids, pyruvic-acid, and C-2-C-3 alpha-dicarbonyls in wet precipitation and aerosol samples by capillary GC and GC/MS, Anal. Chem., 65, 3505-3511, doi:10.1021/ac00071a030, 1993a.

Kawamura, K. and Ikushima, K.: Seasonal-changes in the distribution of dicarboxylic-acids in the urban atmosphere, Environ. Sci. Technol., 27, 2227-2235, doi:10.1021/es00047a033, 1993.

Kawamura, K. and Usukura, K.,: Distribution of low molecular weight dicarboxylic acids in the north pacific aerosol samples, J. Oceanogr., 49, 271-283, 1993b

Kawamura, K. and Yasui, O.: Diurnal changes in the distribution of dicarboxylic acids, ketocarboxylic acids and dicarbonyls in the urban Tokyo atmosphere, Atmos. Environ., 391, 1945-1960, doi:10.1016/j.atmosenv.2004.12.014, 2005.

Kawamura, K., Kasukabe, H., and Barrie, L. A.: Secondary formation of water-soluble organic acids and alpha-dicarbonyls and their contributions to total carbon and water-soluble organic carbon, Photochemical aging of organic aerosols in the Arctic spring, J. Geophys. Res.-Atmos., 115, D21306, doi:10.1029/2010jd014299, 2010.

Kawamura, K., Okuzawa, K., Aggarwal, S. G., Irie, H., Kanaya, Y., and Wang, Z.: Determination of gaseous and particulate carbonyls (glycolaldehyde, hydroxyacetone, glyoxal, methylglyoxal, nonanal and decanal) in the atmosphere at Mt. Tai, Atmos. Chem. Phys., 13, 5369-5380, doi:10.5194/acp-13-53692013, 2013.

Kieber, D. J. and Mopper, K.: Photochemical fromation of glyoxylic and pyruvic acid in seawater, Mar. Chem., 21, 135-149, doi:10.1016/0304-4203(87)90034-x, 1987.

Kieber, R. J., Zhou, X. L., and Mopper, K.: Formation of carbonylcompounds from UV-induced photodegradation of humic substances in natural-waters - fate of riverine carbon in the sea, Limnol. Oceanogr., 35, 1503-1515, 1990.

Li, Y. C. and Yu, J. Z.: Simultaneous determination of mono- and dicarboxylic acids, omega-oxo-carboxylic acids, midchain ketocarboxylic acids, and aldehydes in atmospheric aerosol samples, Environ. Sci. Technol., 39, 7616-7624, doi:10.1021/es050896d, 2005.

Liggio, J., Li, S. M., and McLaren, R.: Reactive uptake of glyoxal by particulate matter, J. Geophys. Res.-Atmos., 110, D10304, doi:10.1029/2004jd005113, 2005.

Liggio, J. and McLaren, R.: An optimized method for the determination of volatile and semi-volatile aldehydes and ketones in ambient particulate matter, Int. J. Environ. An. Ch., 83, 819-835, doi:10.1080/03067310310001597653, 2003.

Lim, Y. B., Tan, Y., Perri, M. J., Seitzinger, S. P., and Turpin, B. J.: Aqueous chemistry and its role in secondary organic aerosol (SOA) formation, Atmos. Chem. Phys., 10, 1052110539, doi:10.5194/acp-10-10521-2010, 2010.

Liss., P. S. and Duce, R. A.: The Sea Surface and Global Change, Cambridge University Press, vCambridge, UK, 1997 RAD, The Sea Surface and Global Change, 1997.

Mbukwa, E. A., Msagati, T. A. M., and Mamba, B. B.: Supported liquid membrane-liquid chromatography-mass spectrometry analysis of cyanobacterial toxins in fresh water systems, Phys. Chem. Earth, 50, 84-91, doi:10.1016/j.pce.2012.09.005, 2012.

Miyazaki, Y., Kawamura, K., and Sawano, M.: Size distributions and chemical characterization of water-soluble organic aerosols over the western North Pacific in summer, J. Geophys. Res.Atmos., 115, D23210, doi:10.1029/2010jd014439, 2010.

Müller, K., Lehmann, S., van Pinxteren, D., Gnauk, T., Niedermeier, N., Wiedensohler, A., and Herrmann, H.: Particle characterization at the Cape Verde atmospheric observatory during the 2007 RHaMBLe intensive, Atmos. Chem. Phys., 10, 2709-2721, doi:10.5194/acp-10-2709-2010, 2010.

Ortiz, R., Hagino, H., Sekiguchi, K., Wang, Q. Y., and Sakamoto, K.: Ambient air measurements of six bifunctional carbonyls in a suburban area, Atmos. Res., 82, 709-718, doi:10.1016/j.atmosres.2006.02.025, 2006.

Pang, X., Lewis, A. C., and Ródenas-Garcia M.: Microfluidic labon-a-chip derivatization for gaseous carbonyl analysis, J. Chromatogr. A, 1296, 93-103, 2013

Pavuluri, C. M., Kawamura, K., and Swaminathan, T.: Watersoluble organic carbon, dicarboxylic acids, ketoacids, and alphadicarbonyls in the tropical Indian aerosols, J. Geophys. Res.Atmos., 115, D11302, doi:10.1029/2009jd012661, 2010.

Rinaldi, M., Decesari, S., Carbone, C., Finessi, E., Fuzzi, S., Ceburnis, D., O’Dowd, C. D., Sciare, J., Burrows, J. P., Vrekoussis, M., Ervens, B., Tsigaridis, K., and Facchini, M. C.: Evidence of a natural marine source of oxalic acid and a possible link to glyoxal, J. Geophys. Res.-Atmos., 116, D16204, doi:10.1029/2011jd015659, 2011.

Saison, D., De Schutter, D. P., Delvaux, F., and Delvaux, F. R.: Determination of carbonyl compounds in beer by derivatisation and headspace solid-phase microextraction in combination with gas chromatography and mass spectrometry, J. Chromatogr. A, 26, 5061-5068, doi:10.1016/j.chroma.2009.04.077, 2009.

Shaw, S. L., Gantt, B., and Meskhidze, N.: Production and Emissions of Marine Isoprene and Monoterpenes, A Review, Adv. Meteorol., 24, 408696, doi:10.1155/2010/408696, 2010.

Sinreich, R., Coburn, S., Dix, B., and Volkamer, R.: Ship-based detection of glyoxal over the remote tropical Pacific Ocean, Atmos. Chem. Phys., 10, 11359-11371, doi:10.5194/acp-1011359-2010, 2010.

Standard Method Number 6252B: "PFBHA Liquid-Liquid Extraction Gas Chromatographic Method", Standard Methods for the Examination of Water and Wastewater, 6-83, American Public Health Assoc., Washington, DC, 1995.

Stolle, C., Nagel, K., Labrenz, M., and Jürgens, K.: Succession of the sea-surface microlayer in the coastal Baltic Sea under natural and experimentally induced low-wind conditions, Biogeosciences, 7, 2975-2988, doi:10.5194/bg-7-2975-2010, 2010.

Tilgner, A. and Herrmann, H.: Radical-driven carbonyl-to-acid conversion and acid degradation in tropospheric aqueous systems studied by CAPRAM, Atmos. Environ., 44, 5415-5422, doi:10.1016/j.atmosenv.2010.07.050, 2010.

Turekian, V. C., Macko, S. A., and Keene, W. C.: Concentrations, isotopic compositions, and sources of size-resolved, particulate organic carbon and oxalate in near-surface marine air at Bermuda during spring, J. Geophys. Res.-Atmos., 108, 4157, doi:10.1029/2002jd002053, 2003.

van Pinxteren, D., Bruggemann, E., Gnauk, T., Iinuma, Y., Muller, K., Nowak, A., Achtert, P., Wiedensohler, A., and Herrmann, H.: Size- and time-resolved chemical particle characterization during CAREBeijing-2006, Different pollution regimes and diurnal profiles, J. Geophys. Res.-Atmos., 114, D00g09, doi:10.1029/2008jd010890, 2009. 
van Pinxteren, M., Müller, C., Iinuma, Y., Stolle, C., and Herrmann, H.: Chemical Characterization of Dissolved Organic Compounds from Coastal Sea Surface Micro layers (Baltic Sea, Germany), Environ. Sci. Technol., 46, 10455-10462, doi:10.1021/es204492b, 2012.

Volkamer, R., Martini, F. S., Molina, L. T., Salcedo, D., Jimenez, J. L., and Molina, M. J.: A missing sink for gas-phase glyoxal in Mexico City, Formation of secondary organic aerosol, Geophys. Res. Lett., 34, L19807, doi:10.1029/2007g1030752, 2007.

Warneck, P.: In-cloud chemistry opens pathway to the formation of oxalic acid in the marine atmosphere, Atmos. Environ., 37, 2423-2427, doi:10.1016/s1352-2310(03)00136-5, 2003.
Whipple, E. B.: Structure of glyoxal in water, J. Am. Chem. Soc., 92, 7183-7186, doi:10.1021/ja00727a027, 1970.

Zhou, X. L. and Mopper, K.: Apparent partition-coefficients of 15 carbonyl-compounds between air and seawater and between air and fresh-water - implications for air sea exchange, Environ. Sci. Technol., 24, 1864-1869, doi:10.1021/es00082a013, 1990.

Zhou, X. L. and Mopper, K.: Photochemical production of lowmolecular-weight carbonyl compounds in seawater and surface microlayer and their air-sea exchange, Mar. Chem., 56, 201-213, doi:10.1016/s0304-4203(96)00076-x, 1997. 